\title{
Desflurane consumption during automated closed-circuit delivery is higher than when a conventional anesthesia machine is used with a simple vaporizer- $\mathrm{O}_{2}-\mathrm{N}_{2} \mathrm{O}$ fresh gas flow sequence
} Sofie De Cooman ${ }^{1}$, Nathalie De Mey², Bram BC Dewulf2, Rik Carette ${ }^{2}$, Thierry Deloof ${ }^{2}$, Maurice Sosnowski ${ }^{1}$, Andre M De Wolf ${ }^{3}$ and Jan FA Hendrickx*2

\author{
Address: ${ }^{1}$ Department of Anesthesiology, Institut Jules Bordet, Université Libre de Bruxelles (U.L.B.), Brussels, Belgium, ${ }^{2}$ Department of \\ Anesthesiology, Intensive Care and Pain Therapy, Onze Lieve Vrouw Hospital, Aalst, Belgium and ${ }^{3}$ Department of Anesthesiology, Feinberg School \\ of Medicine, Northwestern University, Chicago, Illinois, USA \\ Email: Sofie De Cooman - decoomansofie@yahoo.com; Nathalie De Mey - natdemey@hotmail.com; \\ Bram BC Dewulf - bramdewulf@hotmail.com; Rik Carette - rikcarette@yahoo.com; Thierry Deloof - Thierry.deloof@olvz-aalst.be; \\ Maurice Sosnowski - maurice.sosnowski@bordet.be; Andre M De Wolf - a-dewolf@northwestern.edu; \\ Jan FA Hendrickx* - jenwahendrickx@yahoo.com \\ * Corresponding author
}

Published: 17 July 2008

BMC Anesthesiology 2008, 8:4 doi:10.1186/147I-2253-8-4

This article is available from: http://www.biomedcentral.com/I47I-2253/8/4

(C) 2008 De Cooman et al; licensee BioMed Central Ltd.

This is an Open Access article distributed under the terms of the Creative Commons Attribution License (http://creativecommons.org/licenses/by/2.0), which permits unrestricted use, distribution, and reproduction in any medium, provided the original work is properly cited.

\begin{abstract}
Background: The Zeus ${ }^{\circledR}$ (Dräger, Lübeck, Germany), an automated closed-circuit anesthesia machine, uses high fresh gas flows (FGF) to wash-in the circuit and the lungs, and intermittently flushes the system to remove unwanted $\mathrm{N}_{2}$. We hypothesized this could increase desflurane consumption to such an extent that agent consumption might become higher than with a conventional anesthesia machine (Anesthesia Delivery Unit $\left[A D U^{\circledR}\right]$, GE, Helsinki, Finland) used with a previously derived desflurane- $\mathrm{O}_{2}-\mathrm{N}_{2} \mathrm{O}$ administration schedule that allows early FGF reduction.

Methods: Thirty-four ASA PS I or II patients undergoing plastic, urologic, or gynecologic surgery received desflurane in $\mathrm{O}_{2} / \mathrm{N}_{2} \mathrm{O}$. In the ADU group $(\mathrm{n}=24)$, an initial 3 min high FGF of $\mathrm{O}_{2}$ and $\mathrm{N}_{2} \mathrm{O}\left(2\right.$ and $4 \mathrm{~L}^{-m^{-1}}$, respectively) was used, followed by $0.3 \mathrm{~L} \cdot \mathrm{min}^{-1} \mathrm{O}_{2}+0.4 \mathrm{~L}_{\mathrm{Lin}} \mathrm{mi}^{-1} \mathrm{~N}$. The desflurane vaporizer setting $\left(\mathrm{F}_{\mathrm{D}}\right)$ was $6.5 \%$ for the first $15 \mathrm{~min}$, and $5.5 \%$ during the next $25 \mathrm{~min}$. In the Zeus group $(\mathrm{n}=10)$, the Zeus ${ }^{\circledR}$ was used in automated closed circuit anesthesia mode with a selected end-expired $\left(\mathrm{F}_{\mathrm{A}}\right)$ desflurane target of $4.6 \%$, and $\mathrm{O}_{2} / \mathrm{N}_{2} \mathrm{O}$ as the carrier gases with a target inspired $\mathrm{O}_{2} \%$ of $30 \%$. Desflurane $\mathrm{F}_{\mathrm{A}}$ and consumption during the first 40 min were compared using repeated measures one-way ANOVA.

Results: Age and weight did not differ between the groups $(P>0.05)$, but patients in the Zeus group were taller $(P=0.04)$. In the Zeus group, the desflurane $F_{A}$ was lower during the first $3 \mathrm{~min}(P<0.05)$, identical at $4 \mathrm{~min}(P$ $>0.05)$, and slightly higher after $4 \mathrm{~min}(P<0.05)$. Desflurane consumption was higher in the Zeus group at all times, a difference that persisted after correcting for the small difference in $F_{A}$ between the two groups.

Conclusion: Agent consumption with an automated closed-circuit anesthesia machine is higher than with a conventional anesthesia machine when the latter is used with a specific vaporizer-FGF sequence. Agent consumption during automated delivery might be further reduced by optimizing the algorithm(s) that manages the initial FGF or by tolerating some $\mathrm{N}_{2}$ in the circuit to minimize the need for intermittent flushing.
\end{abstract}




\section{Background}

Low flow techniques reduce anesthetic agent consumption but are often perceived as cumbersome. First, frequent vaporizer $\left(\mathrm{F}_{\mathrm{D}}\right)$ or fresh gas flow (FGF) adjustments are thought to be needed, especially at the beginning, when initial wash-in and high uptake by the patient rapidly alter the concentrations of anesthetic gases in the circle system. Second, when FGF is lowered below minute ventilation, a discrepancy develops between the delivered and the inspired concentrations of gases and vapors, which has been considered as "lack of control". Finally, the older literature has been preoccupied by the use of rather complex uptake models to administer these agents with closed-circuit anesthesia (CCA) techniques. The administration schedules in the appendix of the monograph by Lowe and Ernst are daunting to the clinician [1]. The Zeus $^{\circledR}$ anesthesia machine (Dräger, Lübeck, Germany) black-boxes these issues for the clinician by administering inhaled agents by automated closed-loop end-expired feedback [2]. However, the Zeus ${ }^{\circledast}$ also has to use a high FGF, initially to wash-in the circuit and the lungs, and later to intermittently flush the circuit to remove unwanted $\mathrm{N}_{2}$. Because this use of high FGF periods increases desflurane consumption above true CCA conditions, we hypothesized that desflurane consumption with a conventional anesthesia machine $\left(\mathrm{ADU}^{\circledR}\right.$ or Anesthesia Delivery Unit, GE, Helsinki, Finland) might be lower than with the Zeus ${ }^{\circledast}$ if used with a previously derived desflurane- $\mathrm{O}_{2}-\mathrm{N}_{2} \mathrm{O} \mathrm{F}_{\mathrm{D}}$-FGF schedule that allows very early FGF reduction $[3,4]$. The desflurane concentrations resulting from the use of that particular administration schedule with the ADU anesthesia machine have been presented [4], and in this manuscript we present only those data pertinent to the current study.

\section{Methods}

After obtaining IRB approval and informed consent, 36 ASA PS I or II patients undergoing plastic, urologic, or gynecologic surgery were enrolled. All patients received oral alprazolam $1 \mathrm{~h}$ before the scheduled start of surgery. After preoxygenation ( $8 \mathrm{~L} . \mathrm{min}^{-1} \mathrm{O}_{2}$ FGF for $3 \mathrm{~min}$ ), propofol (3 mg. $\left.\mathrm{kg}^{-1}\right)$, rocuronium $\left(0.7 \mathrm{mg} . \mathrm{kg}^{-1}\right)$, and sufentanil $\left(0.1 \mu \mathrm{g} . \mathrm{kg}^{-1}\right)$ were administered intravenously. After intubation of the trachea, ventilation was mechanically controlled. Initial tidal volume and respiratory rate was 500 $\mathrm{mL}$ and 10 breaths per minute, respectively; these settings were later adjusted at the discretion of the attending anesthesiologist. Anesthesia was maintained with desflurane in $\mathrm{O}_{2}-\mathrm{N}_{2} \mathrm{O}$, and additional sufentanil was allowed to be given. Patients were assigned to one of two groups, depending on the anesthesia machine and low flow technique that was used.

In the ADU group $(\mathrm{n}=26)$, an ADU anesthesia machine (Anesthesia Delivery Unit, GE, Helsinki, Finland) was used. Desflurane and $\mathrm{O}_{2}-\mathrm{N}_{2} \mathrm{O}$ were administered with a particular two-step vaporizer-FGF sequence, details of which have been previously described [4]. Briefly, an initial 3 min high FGF of $\mathrm{O}_{2}$ and $\mathrm{N}_{2} \mathrm{O}\left(2\right.$ and 4 L.min ${ }^{-1}$, respectively) was followed by $0.3 \mathrm{~L} \cdot \mathrm{min}^{-1} \mathrm{O}_{2}+0.4 \mathrm{~L} \cdot \mathrm{min}^{-1}$ $\mathrm{N}_{2} \mathrm{O}$. In patients weighing more than $95 \mathrm{~kg}$, a 4 min high FGF period was used. Desflurane $\mathrm{F}_{\mathrm{D}}$ was $6.5 \%$ for the first $15 \mathrm{~min}$, and 5.5\% during the next $25 \mathrm{~min}$. In- and expiratory gases were analyzed by a multigas analyzer (DatexOhmeda Compact Airway Module M-CAiOV, DatexOhmeda, Helsinki, Finland) and downloaded in a spreadsheet every minute. Gases sampled by the multigas analyzer ( $\left.200 \mathrm{~mL} \cdot \mathrm{min}^{-1}\right)$ were not redirected to the anesthesia circuit to avoid $\mathrm{N}_{2}$ accumulation [5]. In the Zeus group ( $\mathrm{n}$ $=10$ ), the automated CCA mode was selected with a desflurane $\mathrm{F}_{\mathrm{A}}$ target of $4.6 \%$ and $\mathrm{O}_{2}-\mathrm{N}_{2} \mathrm{O}$ as the carrier gas with an $\mathrm{F}_{\mathrm{I}} \mathrm{O}_{2}$ target of $30 \% ; 4.5 \%$ could not be selected because the desflurane target can only be increased with $0.2 \%$ increments. Concentrations of the in- and expiratory gases and agent use were downloaded via the proprietary software in a spreadsheet every minute.

Desflurane consumption with the Zeus ${ }^{\circledast}$ machine was retrieved form the amount of agent the injector has injected into the anesthesia circle system, information that was downloaded to a laptop computer in an Excel file every 10 seconds. With the ADU ${ }^{\circledR}$, desflurane consumption was first calculated as $\mathrm{mL}$ vapor from FGF and vaporizer output (not dialed concentrations); this amount of vapor is easily converted to $\mathrm{mL}$ liquid desflurane $(1 \mathrm{~mL}$ liquid desflurane equals $209.3 \mathrm{~mL}$ vapor at $20^{\circ} \mathrm{C}$ ). The same ADU anesthesia machine was used throughout the study. Vaporizer output was intermittently measured at the common gas outlet, and could be related to the dialed concentration as [desflurane vaporizer output $(\%)=0.10$ $+0.97^{*}$ vapor setting] - see reference 4 for details.

All results are presented as mean \pm standard deviation. Desflurane consumption (retrieved directly from both machines) and desflurane $\mathrm{F}_{\mathrm{A}}$ during the first 40 min were compared using repeated measures one-way ANOVA, with $\mathrm{P}<0.05$ indicating statistical significance.

\section{Results}

Age, height, weight, and Body Mass Index (BMI) were 54 \pm 12 years, $167 \pm 8 \mathrm{~cm}, 73 \pm 12 \mathrm{~kg}$, and $24 \pm 6 \mathrm{~kg} / \mathrm{m}^{2}$ in the ADU and $51 \pm 16$ years, $174 \pm 9 \mathrm{~cm}, 73 \pm 17 \mathrm{~kg}$, and $24 \pm 4 \mathrm{~kg} / \mathrm{m}^{2}$ the Zeus group, respectively. Age, weight, and BMI did not differ between the groups $(\mathrm{P}>0.05)$, but patients in the Zeus group were taller $(\mathrm{P}=0.04)$.

In the ADU group, $\mathrm{F}_{\mathrm{A}}$ des was $3.71 \pm 0.40 \%$ after $1 \mathrm{~min}$, reached $4.53 \pm 0.38 \%$ after 2 min and 40 seconds, and fell to a nadir of $4.03 \pm 0.39 \% 4 \mathrm{~min}$ after lowering the FGF (figure 1); after $15 \mathrm{~min}, \mathrm{~F}_{\mathrm{A}}$ des had gradually increased to 


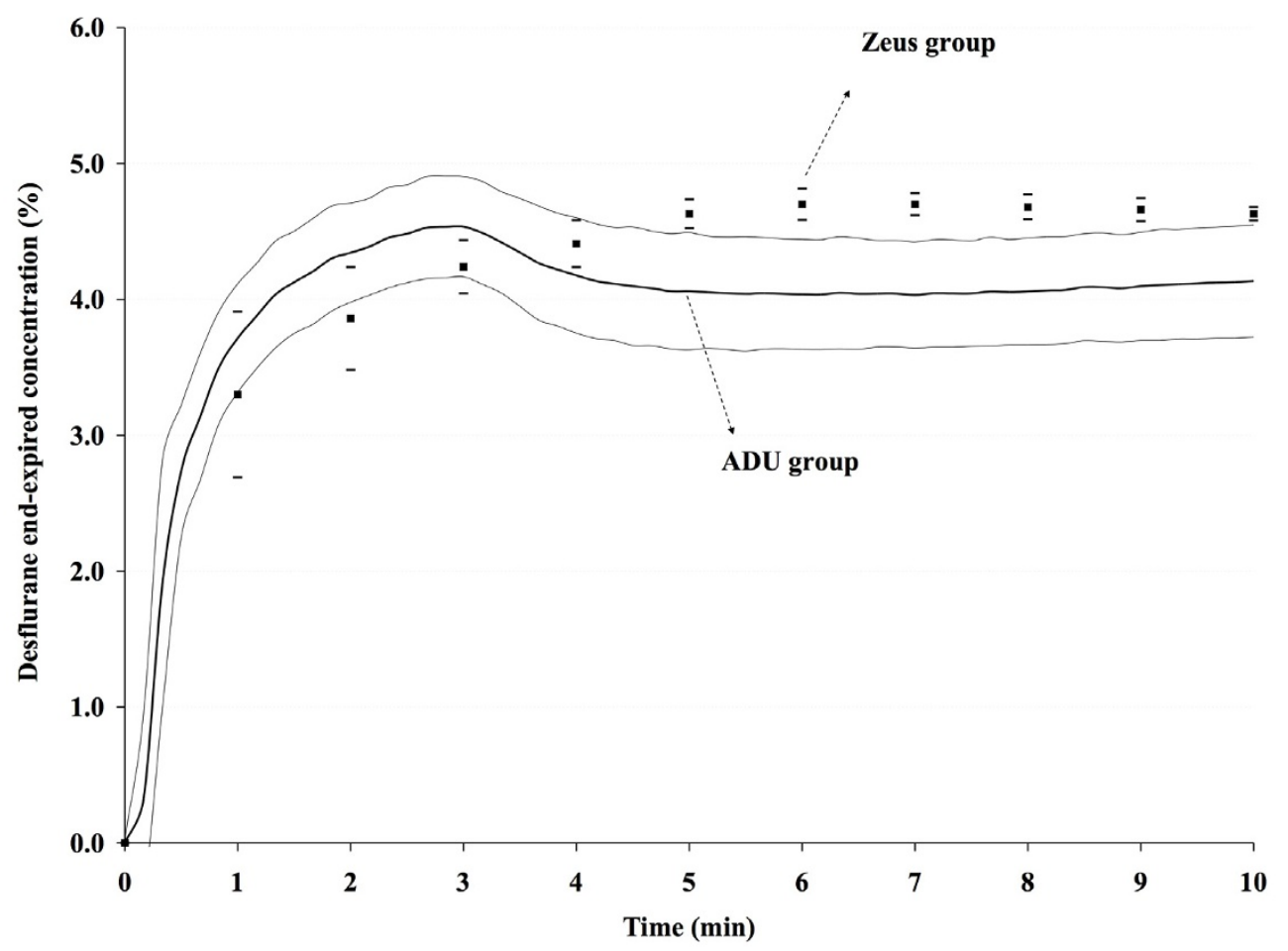

\section{Figure I}

End-expired desflurane concentrations $\left(F_{A}, \%\right)$ with the vaporizer-fresh gas flow sequence (ADU group) or with automated closed-circuit anesthesia (Zeus ${ }^{\circledR}$ group). Results are presented as mean \pm standard deviation.

$4.40 \pm 0.44 \%$ and remained almost constant during the ensuing $30 \mathrm{~min}(4.50 \pm 0.36 \%$ after $45 \mathrm{~min})$. The average desflurane $\mathrm{F}_{\mathrm{A}}$ of all patients combined between 5 and 40 min was $4.41 \%$ (standard deviation 0.43 ), slightly lower than the $4.6 \%$ target in the Zeus group. The course of $\mathrm{F}_{\mathrm{A}} \mathrm{N}_{2} \mathrm{O}$ and $\mathrm{F}_{\mathrm{A}} \mathrm{N}_{2}$ in the ADU group are presented in figure 2.

In the Zeus group, desflurane $\mathrm{F}_{\mathrm{A}}$ (figure 1) was lower than in the ADU group during the first 3 min $(P<0.05)$, identical at 4 min $(P>0.05)$, and slightly higher after 4 min ( $P$ $<0.05)$. The $\mathrm{F}_{\mathrm{A}}$ target was maintained at $4.6 \%$ after $4 \mathrm{~min}$ in all patients in the Zeus group. In the Zeus group, the course of $\mathrm{F}_{\mathrm{A}} \mathrm{N}_{2} \mathrm{O}$ is less consistent between patients than in the ADU group (compare figures 2 and 3 ) because high and low FGF alternate, steered by the proprietary algorithms of the Zeus ${ }^{\circledast}$ to combine the goals of achieving the desired target concentrations of the anesthetic gases and minimizing agent and gas consumption. A typical example of fresh gas flow management by the Zeus ${ }^{\circledast}$ and resulting in-expired $\mathrm{O}_{2}\left(\mathrm{~F}_{\mathrm{I}} \mathrm{O}_{2}\right)$, end-expired $\mathrm{N}_{2} \mathrm{O}\left(\mathrm{F}_{\mathrm{A}} \mathrm{N}_{2} \mathrm{O}\right)$, and inspired $\mathrm{N}_{2}\left(\mathrm{~F}_{\mathrm{I}} \mathrm{N}_{2}\right)$ concentrations are presented in figure 3.
Desflurane consumption was higher in the Zeus than in the ADU group at all times (Table 1); this difference persisted after correcting for the small difference in $\mathrm{F}_{\mathrm{A}}$ between the two groups.

\section{Discussion}

The use of a specific desflurane- $\mathrm{O}_{2}-\mathrm{N}_{2} \mathrm{O} \mathrm{F}_{\mathrm{D}}$-FGF sequence with a conventional anesthesia machine provides comparable end-expired desflurane concentrations and reduces desflurane consumption below that with an automated CCA machine, or alternatively, desflurane consumption during automated closed-circuit delivery is higher than with a conventional anesthesia machine if the latter is used with a particular vaporizer- $\mathrm{O}_{2}-\mathrm{N}_{2} \mathrm{O}$ fresh gas flow sequence.

The performance of the Zeus ${ }^{\circledast}$ has been described in vitro, and compared with the Primus ${ }^{\boxplus}$ (Dräger, Lübeck, Germany) [2]. The target desflurane $\mathrm{F}_{\mathrm{A}}$ was attained slightly later with the Zeus ${ }^{\circledast}$ because part of the fresh gas goes directly to the patient with the Primus ${ }^{\circledR}$, while fresh gas is extensively mixed in the circle system before reaching the patient in the Zeus ${ }^{\circledast}[2]$. The ADU ${ }^{\circledast}$ design (with the FGF 


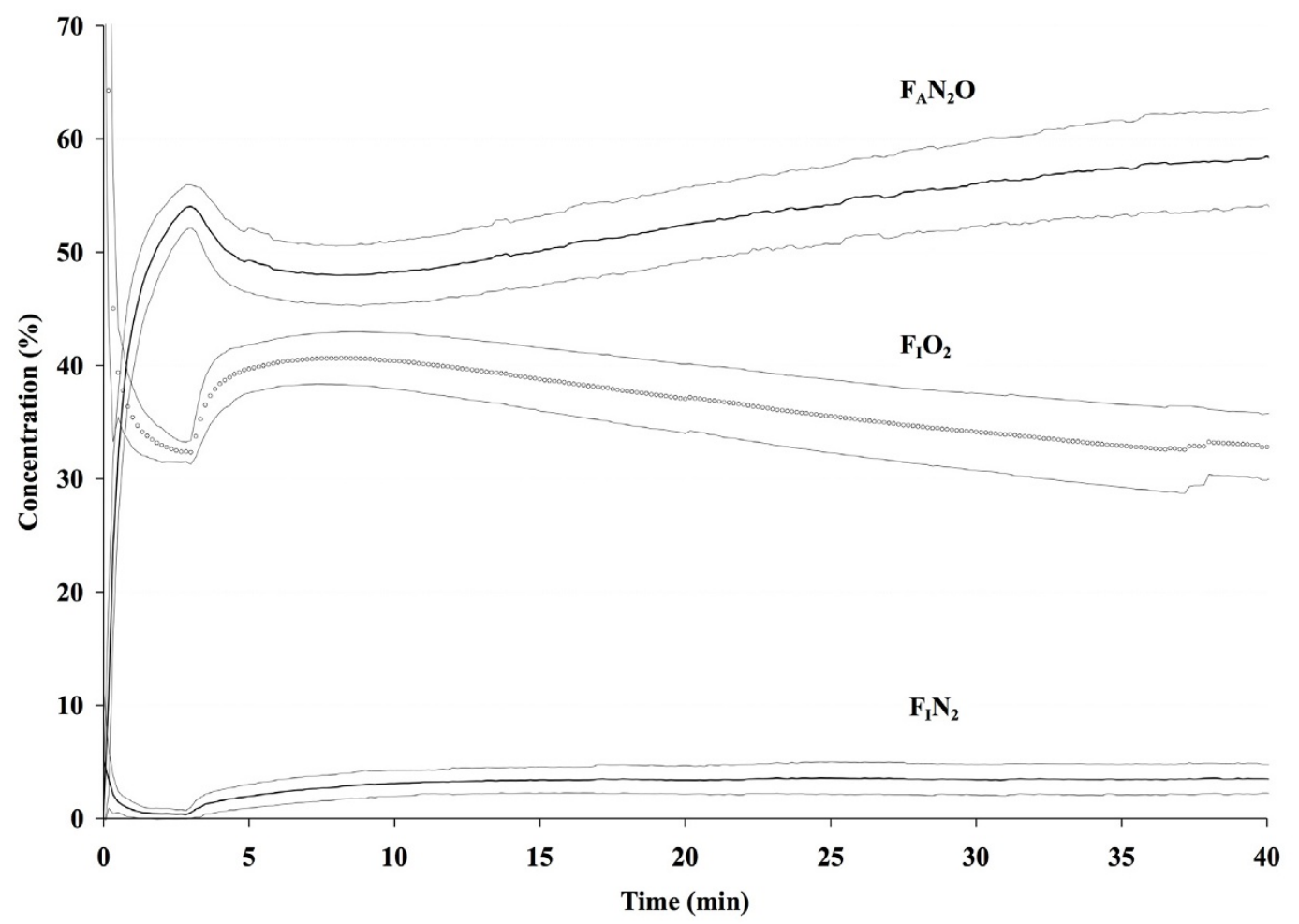

Figure 2

Inspired $\mathrm{O}_{2}\left(F_{1} \mathrm{O}_{2}\right)$, end-expired $\mathrm{N}_{2} \mathrm{O}\left(\mathrm{F}_{\mathrm{A}} \mathrm{N}_{2} \mathrm{O}\right)$, and inspired $\mathrm{N}_{2}\left(\mathrm{~F}_{1} \mathrm{~N}_{2}\right)$ concentrations with a conventional anesthesia machine (ADU $\left.{ }^{\circledR}\right)$. Results are presented as mean \pm standard deviation.

inflow located just distal to the inspiratory valve) also explains the slightly faster rise of $\mathrm{F}_{\mathrm{A}}$ desflurane in the ADU group. After wash-in, $\mathrm{F}_{\mathrm{A}}$ desflurane is maintained within a slightly narrower range with the Zeus ${ }^{\circledR}$ than with the 0.7 L. min $^{-1}$ FGF with the ADU ${ }^{\circledast}$ (figure 1). More details regarding the performance characteristics of the $\mathrm{F}_{\mathrm{D}}$-FGF sequence can be found elsewhere [4].

Even though it is well known that the initial high FGF period is a major determinant of vapor and gas consumption, many anesthesiologists continue to use high FGF initially because low flow techniques have been perceived as particularly cumbersome to use at the beginning of an anesthetic. Because the initial wash-in and high uptake by the patient rapidly alter the concentrations of anesthetic gases in the circle system, the need for frequent vaporizer and rotameters adjustments required when using low FGF has been claimed to be too distracting at a time when the anesthesiologist is preoccupied by other tasks. Like Lerou [6], we therefore argue that a simple, clinically easy to apply $\mathrm{F}_{\mathrm{D}}$-FGF schedule as used in our ADU group could encourage anesthesiologists to more frequently use lower FGF early on during the anesthetic. With a conventional machine with ascending visible bellows (e.g. the $\mathrm{ADU}^{\circledR}$ ), the acceptance of a small temporary bellows deficit allows for early FGF reduction (after $3 \mathrm{~min}$ ), and the small amount of FGF in excess of patient uptake and gas sampling during maintenance slowly washes out $\mathrm{N}_{2}$ yet contributes little to overall desflurane consumption. The somewhat unexpected finding that agent consumption is higher with the Zeus ${ }^{\circledR}$ than with the ADU ${ }^{\circledR}$ is the result of two factors: the use of a very high initial FGF (>11 L/min) and the intermittent flushing of the gas reservoir when $\mathrm{N}_{2}$ concentration reaches a certain threshold. The effect of the first factor is readily demonstrated by calculating the effect on desflurane consumption of shortening the high FGF period by one min. With the described $\mathrm{F}_{\mathrm{D}}$-FGF sequence with the $\mathrm{ADU}^{\circledast}$, desflurane consumption is $12.8 \mathrm{~mL}$ after 40 min; when the duration of high FGF is extended by one min, total consumption increases to $14.4 \mathrm{~mL}$. If the high FGF would be extended by another 2 minutes, desflurane consumption would become similar to that with the Zeus $^{\circledast}$. The second important factor that explains the difference in agent consumption is the difference in the manner the two techniques handle $\mathrm{N}_{2}$. With the conventional anesthesia machine, gases sampled by the agent analyzer 


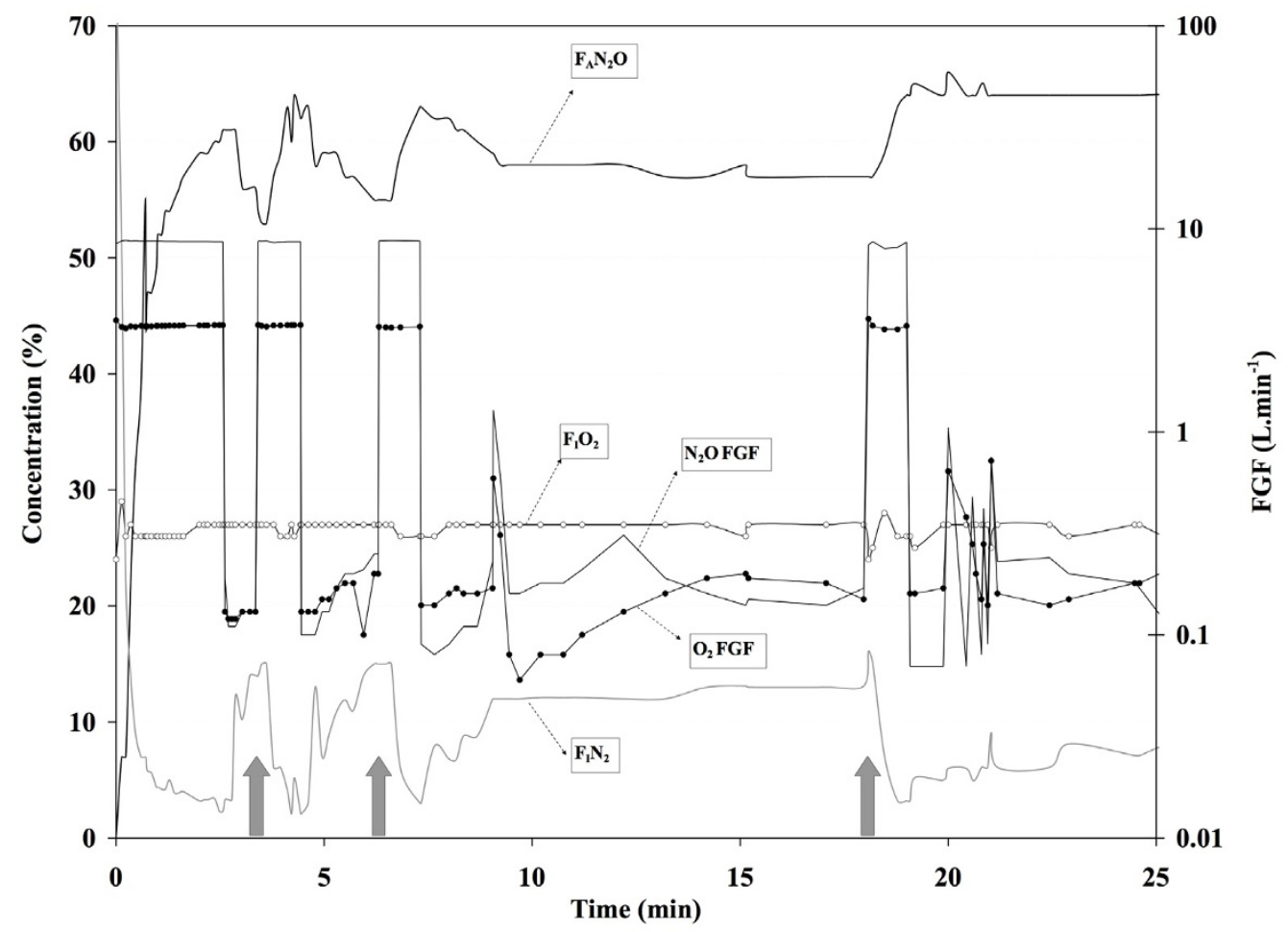

Figure 3

Example of fresh gas flow management by the Zeus ${ }^{\circledR}$ and resulting inspired $\mathrm{O}_{2}\left(\mathrm{~F}_{1} \mathrm{O}_{2}\right)$, end-expired $\mathrm{N}_{2} \mathrm{O}$ $\left(\mathbf{F}_{\mathbf{A}} \mathbf{N}_{\mathbf{2}} \mathbf{O}\right.$ ), and $\mathbf{N}_{\mathbf{2}}\left(\mathbf{F}_{1} \mathbf{N}_{2}\right)$ concentrations. Note how during automated administration the $\mathrm{FGF}$ of $\mathrm{O}_{2}$ and $\mathrm{N}_{2} \mathrm{O}$ (right $\mathrm{Y}$-axis, logarithmic scale) is increased whenever $\mathrm{F}_{1} \mathrm{~N}_{2}$ increases above a threshold value of approximately I5\% (grey arrows).

(200 $\left.\mathrm{mL} \cdot \mathrm{min}^{-1}\right)$ are not redirected to the anesthesia circuit (avoiding air entrainment by the gas analyzer into the circuit at a rate of $32 \mathrm{~m} \mathrm{~L} \cdot \mathrm{min}^{-1}$ [5]), and the 0.7 L.min ${ }^{-1}$ maintenance FGF used with the $\mathrm{F}_{\mathrm{D}}$-FGF sequence therefore ensures that $\mathrm{N}_{2}$ concentration in the circuit remains very low and even continues to decrease despite a rela-

Table I: Desflurane consumption (cumulative dose, $\mathrm{mL}$ liquid) was higher at all times $(P<0.05)$ during automated closedcircuit anesthesia administration (Zeus ${ }^{\circledR}$ ) than with a conventional machine used with the predefined low flow sequence $\left(A D U^{\circledR}\right)$.

\begin{tabular}{ccc}
\hline Time $(\mathrm{min})$ & ADU group & Zeus group \\
\hline 0 & $0.0 \pm 0.0$ & $0.0 \pm 0.0$ \\
5 & $6.0 \pm 0.0$ & $11.7 \pm 4.0$ \\
10 & $7.1 \pm 0.0$ & $12.9 \pm 4.1$ \\
15 & $8.2 \pm 0.0$ & $13.9 \pm 4.2$ \\
20 & $9.1 \pm 0.2$ & $14.8 \pm 4.5$ \\
25 & $10.0 \pm 0.3$ & $15.4 \pm 4.3$ \\
30 & $11.0 \pm 0.3$ & $15.9 \pm 4.5$ \\
35 & $11.9 \pm 0.3$ & $16.6 \pm 4.6$ \\
40 & $12.8 \pm 0.4$ & $17.2 \pm 4.8$ \\
\hline
\end{tabular}

tively short high FGF period (figure 2). The Zeus ${ }^{\circledR}$ takes a different approach. As soon as possible and whenever possible, it will try to convert to CCA conditions. Closing the circuit will inevitable lead to a subsequent increase in $\mathrm{N}_{2}$ in the anesthesia circuit because vessel rich tissues are still releasing significant amounts of $\mathrm{N}_{2}$. Whenever the $\mathrm{F}_{\mathrm{I}} \mathrm{N}_{2}$ increases above a certain threshold (e.g. $\mathrm{F}_{\mathrm{I}} \mathrm{N}_{2}$ of $15 \%$ ), FGF is increased to flush the circuit (figure 3). Our data indicate that serial flushing to reduce $\mathrm{N}_{2}$ increases agent consumption well above the amount taken up by the patient, to the extent that desflurane consumption with our current $\mathrm{F}_{\mathrm{D}}$-FGF sequence used with a conventional anesthesia machine and a FGF in between minimal flow (0.5 L.min-1) and low flow (1.0 L.min ${ }^{-1}$ ) becomes lower than that with an automated closed-circuit anesthesia machine, that - according to the definition of closed circuit anesthesia - should administer just that amount of agent that is taken up by the patient and lost via circuit leaks. This suggests that administration regimens similar to ours could help steer more conventional anesthesia machines to lower agent consumption similar to or below that of automated closed-loop feedback anesthesia 
machines, or could be used to optimize administration algorithms of automated closed-loop feedback anesthesia machines themselves. Agent consumption by the Zeus ${ }^{\circledR}$ could be further reduced by optimizing the algorithm that manages the initial FGF (e.g. by allowing a more gradual rise towards the desired anesthetic gas concentrations) or by tolerating some $\mathrm{N}_{2}$ in the circuit to minimize the need for high FGF used during intermittent flushing. Our findings also suggest that the actual FGFs used by a particular technique or device should always be explicitly mentioned to allow proper interpretation of terms like "closed-circuit".

\section{Conclusion}

Anesthetic agent consumption with an automated closedcircuit anesthesia machine is higher than with a conventional anesthesia machine if the latter is used with a specific vaporizer-FGF sequence. More specifically, one desflurane vaporizer and one $\mathrm{O}_{2} / \mathrm{N}_{2} \mathrm{O}$ FGF change with a conventional anesthesia machine with ascending visible bellows suffices to maintain satisfactory anesthetic gas concentrations within a clinically sufficiently narrow range during the first $20-30 \mathrm{~min}$ in most patients. The higher consumption with the closed-circuit anesthesia machine is caused by the use of high FGF for initial circuit and lung wash-in and by intermittent flushing of the circuit to reduce $\mathrm{N}_{2}$ accumulation. We therefore suggest that agent consumption during automated delivery can be further reduced by optimizing the algorithm(s) that manages the initial FGF (e.g. by allowing a more gradual rise towards the desired anesthetic gas concentrations) or by tolerating some $\mathrm{N}_{2}$ in the circuit to minimize the need for intermittent flushing.

\section{Competing interests}

The authors declare that they have no competing interests.

\section{Authors' contributions}

Conception and design: JHX, ADW. Acquisition of data, or analysis and interpretation of data: SDC, NDM, BBCD, JHX. Drafting the manuscript or revising it critically: All authors. Given final approval of the final submitted version: All authors.

\section{References}

I. Lowe J, Ernst E: The quantitative practice of anesthesia - use of a closed circuit Baltimore: Williams \& Wilkins; 198I.

2. Struys MMRF, Kalmar AF, De Baerdemaeker LEC, Mortier EP, Rolly G, Manigel J, Buschke W: Time course of inhaled anaesthetic drug delivery using multifunctional closed-circuit anaesthesia ventilator. In vitro comparison with a classical anaesthesia machine. Br J Anaesth 2005, 94:306-3I7.

3. Hendrickx JFA, Cardinael S, Carette R, Lemmens HJ, De Wolf AM: The Ideal $\mathrm{O}_{2} / \mathrm{N}_{2} \mathrm{O}$ Fresh Gas Flow (FGF) Sequence with the Anesthesia Delivery Unit Machine. J Clin Anesth 2007, 1 9:274-279.

4. Hendrickx JFA, Dewulf BBC, De Mey N, Carette R, Deloof T, De Cooman S, De Wolf AM: Development and performance of a two step desflurane $-\mathrm{O}_{2} / \mathrm{N}_{2} \mathrm{O}$ fresh gas flow sequence. J Clin Anesth in press.

5. Hendrickx JFA, Van Zundert AAJ, De Wolf AM: Influence of the reference gas of paramagnetic oxygen analyzers on nitrogen concentrations during closed-circuit anesthesia. J Clin Monit Comp 1998, 14:381-84.

6. Lerou JG, Verheijen R, Booij LH: Model-based administration of inhalation anaesthesia. 4. Applying the system model. $\mathrm{Br} J$ Anaesth 2002, 88: 175-83.

\section{Pre-publication history}

The pre-publication history for this paper can be accessed here:

http://www.biomedcentral.com/1471-2253/8/4/prepub
Publish with BioMed Central and every scientist can read your work free of charge

"BioMed Central will be the most significant development for disseminating the results of biomedical research in our lifetime. " Sir Paul Nurse, Cancer Research UK

Your research papers will be:

- available free of charge to the entire biomedical community

- peer reviewed and published immediately upon acceptance

- cited in PubMed and archived on PubMed Central

- yours - you keep the copyright

Submit your manuscript here:

http://www.biomedcentral.com/info/publishing_adv.asp 